\title{
Los grupos políticos municipales
}

\author{
Antonio Calonge Velázquez \\ Profesor Titular de Derecho Administrativo de la Universidad de Valladolid
}

Sumario: I. INTRODUCCIÓN. II. CONCEPTO. III. NATURALEZA JURÍDICA. IV. NORMAS REGULADORAS. V. RÉGIMEN JURÍDICO. 1. Constitución. 1.1. Obligatoriedad. 1.2. Número mínimo. 1.3. Limitaciones a la libertad de constitución. 1.4. Procedimiento. A) Solicitud. B) Contenido. C) Plazo. D) Publicidad. 2. Funciones y atribuciones. 3. Medios materiales, personales y económicos.

\section{INTRODUCCIÓN}

Desde que surgieran los Ayuntamientos y Diputaciones provinciales democráticos tras las elecciones de marzo de 1979, los grupos políticos locales han sido, primero, una realidad fáctica y, después, un instituto (llamémoslo así, de momento) reconocido y regulado por nuestro ordenamiento jurídico, que por carecer de precedentes en nuestro Derecho histórico supone una novedad más del régimen local.

Lo cierto es que los grupos políticos locales -importantes, sin duda, para la vida ordinaria de nuestras Corporaciones locales- están pasando sin pena ni gloria por las páginas de nuestra literatura jurídica, que apenas dedica — con la salvedad de la excepción que confirma la regla ${ }^{1}$ — unos párrafos, básicamente descriptivos, de su régimen jurídico, cuando realmente constituyen, a nuestro modo de ver, el sistema nervioso de toda institución local, habida cuenta de que todas las iniciativas, posiciones y decisiones parten o pasan por los grupos políticos, que forman — que deben formar, mejor debería expresar- los concejales y diputados provinciales, antes de ser debatidas y adoptadas en el seno del Pleno correspondiente.

Desde que iniciara su andadura la presente etapa constitucional, son numerosos los problemas jurídicos que se han suscitado con estas figuras político-jurídicas y, por ello, existe ya una abundante y detallada jurisprudencia a la que se hará alusión al analizar los distintos apartados en que se estructura el presente trabajo. El mismo concepto, la denominación, la obligatoriedad de su pertenencia, el número mínimo de electos locales que se precisa para constituir un grupo, la expulsión o abandono del grupo por

\footnotetext{
${ }^{1}$ Véase, in totum, el espléndido trabajo de Enrique Belda Pérez-Pedrero, «Los grupos políticos en Ayuntamientos y Diputaciones», $\mathrm{n}^{\circ}$ 51, RDP, 2001, pp. 226-318
} 
uno de sus miembros y su pase a otro, las necesidades personales y materiales para su funcionamiento, el grupo mixto, etc., son sólo algunas de las cuestiones a las que nos deberemos enfrentar a lo largo de las páginas que sigan. Ahora bien, los problemas no se agotan con los que se han planteado hasta el momento, sino que las novedades legislativas en curso ${ }^{2}$ aportan una nueva problemática a la que en su momento se hará mención.

El presente estudio se centra, no obstante, casi con exclusividad, salvo algunas referencia generales obligadas, en los grupos políticos que forman los concejales en los Ayuntamientos, esto es, los grupos políticos municipales, teniendo muy presente que la importancia de éstos está en función de la población municipal $\mathrm{y}$, en consecuencia, del número de concejales que integren la Corporación municipal, de modo que, cuanto mayor sea aquélla más importancia tendrán estos institutos, mientras que en los municipios de población reducida su relevancia será menor porque esta especie de cuerpo intermedio entre la población y los corporativos prácticamente carece de sentido cuando los miembros de la Corporación municipal y los vecinos tienen unas relaciones muy directas ${ }^{3}$.

\section{CONCEPTO}

Resulta obligado partir del concepto de la realidad en que se concretan los grupos municipales objeto del presente estudio, pues en él se encuentran, seguramente, los elementos que conforman o caracterizan esta figura político-jurídica.

Existe un concepto legal de grupo político municipal muy genérico que se contiene en el Reglamento de Organización, Funcionamiento y Régimen Jurídico de las Corporaciones Locales (en adelante, ROF), que fue la

\footnotetext{
2 Me refiero a la Ley 57/2003, de 16 de diciembre, de medidas para la modernización del gobierno local (BOE de 17 de diciembre).

${ }^{3}$ Federico Romero Hernández, «Los grupos políticos en el gobierno municipal», IV Jornadas Canarias sobre la Administración Local, Gobierno de Canarias, Consejería de Presidencia, Santa Cruz de Tenerife, 2000, p. 223, ha expresado esta idea manifestando: «No puede nunca olvidarse en el Régimen local que la presencia del principio de diversidad — dado el distinto tamaño de los Entes Locales - y la mutabilidad de los diversos escenarios políticos en que su vida diaria se produce, hace que la relevancia de estos grupos sean paralelamente muy diversas». En similar sentido se ha expresado Alberto MARTíNEZ SÁNCHEZ, La organización y el funcionamiento municipales, Comares, Granada, 1989, pp. 90 y 91, cuando indica que «La formación de los grupos políticos en los Ayuntamientos está íntimamente relacionada con la necesidad de conseguir un determinado orden en la participación de los concejales en las sesiones de los Plenos y otros órganos colegiados. De ahí que cuanto mayor sea el número de miembros de la corporación más oportuna es la canalización de las intervenciones de los concejales a través de los grupos».
} 
primera norma que con carácter general lo contempló y reguló. Define esta disposición el grupo municipal como el constituido, a efectos de su actuación corporativa, por los miembros de las Corporaciones Locales. Esta definición se nos antoja, sin embargo, pobre y, a todas luces, insuficiente, pues se limita a describir la realidad que debe ser objeto de definición, pero sin apuntar siquiera en presencia de qué tipo de instituto jurídico nos encontramos. Sólo destaca el elemento personal, que deben ser miembros de las Corporaciones Locales, y el finalista, que el grupo o agrupación se hará a efectos de su actuación corporativa.

La Ley 7/1985, de 2 de abril, Reguladora de las Bases de Régimen Local (a partir de ahora LBRL), en su redacción primitiva, sólo lo mencionó, dando por supuesta su existencia, al reconocer en su artículo 20.3 su derecho a participar en las comisiones informativas; no se preocupó de ofrecer una definición, y se limitó a expresar el principio general de que los grupos políticos tienen derecho a participar en los órganos complementarios del Ayuntamiento. La modificación que se operó en esta Ley, mediante la Ley 11/1999, de 21 de abril, tampoco llevó a cabo semejante operación, limitándose a elevar el reconocimiento de los grupos políticos a rango de ley, lo que significó, a todas luces, un reforzamiento de esta figura. En cualquier caso, la simple mención que la LRBRL hace a los grupos políticos no parece haber tenido otro propósito que el de imponer la presencia de las minorías en las actividades preparatorias del debate y decisión de los asuntos a resolver en el Ayuntamiento pleno ${ }^{4}$.

Algún reglamento orgánico municipal de los que se ha tenido ocasión de examinar también ha ensayado una definición de esta realidad. Es el caso del reglamento orgánico del Ayuntamiento de Málaga que, en su artículo 24, dice que por grupos municipales deben entenderse «aquellas unidades políticas constituidas, exclusivamente, por concejales pertenecientes a una misma lista electoral y que, mediante presencia proporcional, instrumentan su participación en los órganos complementarios municipales». Desde luego, la calificación de los grupos municipales como «unidades políticas» no nos resuelve el problema de cuál pueda ser la realidad jurídica ante cuya presencia estamos, ni su alusión a que están integrados «exclusivamente» por concejales pertenecientes a una misma lista electoral o que constituyen instrumentos de participación en los órganos complementarios municipales, nos desvela tampoco las principales características de esta institución.

\footnotetext{
${ }^{4}$ Así se ha expresado - con acierto, en nuestra opinión- Luis Morell OCAÑa, El régimen local español, Civitas, Madrid, 1988, p. 516, pues, no tiene otra explicación que la Ley se haya expresado de manera tan parca respecto de esta figura político-jurídica.
} 
La misma denominación de la realidad en que se materializan los grupos tampoco es única, aunque la más extendida y aceptada plenamente por el Tribunal Constitucional es la de grupo político ${ }^{5}$, en base — como ha manifestado BeLda PÉREZ-PEDRERO- a una interpretación sistemática de las leyes locales, y al tenor literal de los artículos 23 y 24 del $\mathrm{ROF}^{6}$, así como a la propia rúbrica del Capítulo — se debería añadir- de esta disposición donde se contiene su regulación. Ahora bien, también existen leyes autonómicas y reglamentos orgánicos municipales que hablan, de manera expresa, de grupos municipales que será la expresión que más utilizaremos por nosotros en cuanto, como se ha señalado, son preferentemente de los que nos vamos a ocupar.

En la doctrina, los pocos autores que se han ocupado de esta cuestión tampoco se han prodigado en ofrecer un concepto de grupo político, pues son más los que se han limitado a dar cuenta y a analizar su régimen jurídico, que a señalar los elementos y caracteres del instituto político-jurídico que se analiza.

Morell Ocaña ha definido los grupos políticos municipales hasta de tres maneras diferentes, en atención a las funciones que, a su juicio, pueden desempeñar éstos. Así, en cuanto pueden ejercer funciones de apoyo al desempeño de derechos y deberes individuales, los define como «asociaciones de concejales para el ejercicio conjunto de derechos y deberes típi-

\footnotetext{
${ }^{5}$ Véase la Sentencia 30/1993, de 25 de enero, FJ 6. Frente al planteamiento del recurrente, que sostiene que la expresión grupos políticos no puede entenderse referida a los grupos políticos en los que se integran los concejales a los efectos de su actuación corporativa, sino a las formaciones políticas que hayan concurrido a las elecciones y obtenido representación en la Corporación, el alto Tribunal señala que «existen elementos interpretativos... que permiten determinar el significado de la expresión grupos políticos. En primer lugar, la propia noción que de grupos políticos se contiene en la legislación de régimen local, en la que se define aquéllos como los constituidos, a efectos de actuación corporativa, por los miembros de las Corporaciones Locales (artículo 23 ROF)... aunque prescindiéramos de la referida noción legal, igual conclusión se obtendría a partir de una interpretación sistemática de la normativa vigente, pues habiendo optado el legislador como criterio de organización del trabajo de la Corporación, generalizado, por lo demás, en todos los órganos asamblearios, por el encuadramiento en grupos de los concejales que la integran, el derecho garantizado a cada grupo político de participar en los órganos internos de funcionamiento y de tener, como mínimo, un concejal en los mismos, no podría extenderse referido a los grupos constituidos por los concejales, pues de lo contrario quedaría de todo sentido privado aquel criterio de organización. Finalmente, aunque dichos grupos políticos sean frecuentemente una lógica emanación de las formaciones políticas... en cuyas listas han sido elegidos los concejales, la interpretación que postula el recurrente... difícil cabida tiene...».

Véanse, también, las Sentencias del Tribunal Supremo de la Sección $9^{\text {a }}$ de la Sala de lo Contencioso-Administrativo de 28 de junio de 1990 (RJ 1990/5171) y 29 de noviembre de 1990 (RJ 1990/8833) de las que fue ponente el Excmo. Sr. D. César González Mallo.
}

${ }^{6} \ll$ Los grupos políticos...», cit., p. 226. 
cos del cargo»; en ejercicio de una función mediadora, tanto en relación al electorado como con los órganos de la corporación, los contempla como «instrumento de mediación, articulando a los miembros de la Corporación de acuerdo con las tendencias decantadas entre ellos, respecto del gobierno de la colectividad»; $y$, en fin, en cuanto ejercen una función de formación y defensa de una opinión común frente a los problemas de gobierno y administración municipales, los conceptúa como «expresión de las corrientes de opinión o programas de actuación municipal existentes en el seno dela comunidad y que, tras la elección, se expresan en el Ayuntamiento» ${ }^{7}$.

Puede advertirse, pues, que Morell Ocaña ha seguido un criterio funcional para definir los grupos políticos municipales. $\mathrm{O}$, expresado en otros términos, se ha preocupado sólo de las funciones que pueden desempeñar los grupos políticos municipales para expresar una triple definición, pero basada en un único criterio.

Otro autor que se ha ocupado de esta cuestión ha sido Romero HerNÁNDEZ, que, después de afirmar que los grupos políticos deben considerarse como un instituto de naturaleza esencialmente organizativa y que ejercen una función meramente complementaria e instrumental ${ }^{8}$, los define como «aquellos integrados por concejales o diputados de una misma Corporación local, que por razones de comparecencia electoral y/o afinidad política o, incluso, excepcionalmente, de carácter coyuntural (aludimos al Grupo Mixto) instrumentan su actuación corporativa, tanto en la preparación de los asuntos municipales en que intervienen, como en la participación de la formación de la voluntad de los órganos complementarios o necesarios, todo ello sin perjuicio de los derechos individuales que su respectivo estatuto político y jurídicos les confiere» ${ }^{9}$.

Se trata, sin duda, de una definición más completa en la que se utiliza no sólo el criterio funcional, sino también el orgánico, aunque pensamos que la complitud de este concepto y la mezcla de criterios con la intención de abarcar la totalidad de la realidad que define, lo hace de difícil aprehensión.

La Redacción de El Consultor los ha definido de manera ciertamente compleja al señalar que «son órganos colegiados de naturaleza política en

\footnotetext{
${ }^{7}$ L. Morell Ocaña, El régimen local...l, cit., pp. 515-516 y 519-520.

${ }^{8}$ «los grupos políticos en el gobierno...», cit., pp. 224 y 227.

${ }^{9}$ Ibidem, pp. 227 y 228. También en Comentarios a la Ley Básica de Régimen Local, Manuel J. Domingo Zaballos (coordinador), Civitas, Madrid, 2003, p. 367.
} 
los que por imperativo legal se integran los miembros de la Corporación a efectos de organizar sus tareas corporativas» y, también, «asociaciones de concejales más o menos afines ideológicamente o pragmáticamente para agilizar y facilitar el ejercicio de sus derechos y deberes» para concluir afirmando que, «por otra parte, «son instrumentos de mediación» ${ }^{10}$. En fin, tales conceptos, aun siendo útiles para acercarse a un entendimiento de lo que son los grupos municipales, no permiten, no obstante, descubrir la esencia de su carácter, pues son calificados, a la vez, de órganos, asociaciones e instrumentos y, parece lógico entender, que todo no lo puede ser.

Finalmente, Belda Pérez-Pedrero, que ha sido entre nosotros el que más ha estudiado a los grupos políticos locales, atendiendo a lo que considera sus rasgos esenciales: el origen electivo de sus miembros, su investidura como cargos, una ideología o interés común y la permanencia de todos estos caracteres a lo largo del mandato, adelanta una definición afirmando que son un «conjunto de cargos electos que una vez investidos de autoridad, se unen por afinidad de ideas, a efectos de su actuación conjunta en la institución de la que son parte durante una legislatura o un mandato» ${ }^{11}$.

Sin desmerecer a las anteriores esta definición puede considerarse más completa, clara y comprensible de la realidad de los grupos, sobre todo, porque no prejuzga otra cuestión importante que se tratará a continuación como es la de su naturaleza jurídica. El autor citado se limita a constatar que, en efecto, estamos en presencia de un grupo de cargos electos que ya han jurado o prometido el cargo, esto es, que son cargos públicos en plenitud de derechos y deberes y que se unen, a efectos de su actuación corporativa, por afinidad de ideas o intereses durante un período concreto, que es el de una legislatura o mandato. Es decir, la definición ofrecida por este autor contempla todos los elementos que, a nuestro juicio, integran la figura político-jurídica del grupo: por una parte, el elemento personal, es decir, el grupo constituye una realidad integrada por unos miembros de las Corporaciones Locales que tienen la categoría de cargos electos o, mejor expresado, que ya han tomado posesión de los mismos y, en consecuencia, están investidos de autoridad, lo que permitiría hablar de un elemento personal cualificado; por otra, el elemento funcional, ya que este grupo se constituye para un mejor y eficaz funcionamiento de la Corporación Local, a efectos de su actuación corporativa, dice en concreto; en tercer

\footnotetext{
${ }^{10}$ La Redacción de El Consultor, Manual del Concejal, $5^{\text {a }}$ ed., El Consultor de los Ayuntamientos y de los Juzgados, Madrid, 2003, p. 165.

11 «os grupos políticos...», p. 227.
} 
lugar, destaca el elemento lógico, esto es, lo que produce o motiva ese grupo, que es la afinidad de ideas o intereses; y, por último, el elemento temporal, ya que este conjunto de cargos electos no tiene una vocación de permanencia, sino que se constituye para un período concreto cual es el de la legislatura o mandato de la Corporación.

\section{NATURALEZA JURÍDICA}

La naturaleza jurídica de los grupos políticos, en general y, más en concreto, de los grupos parlamentarios, que son los que más profusa y profundamente ha estudiado la doctrina constitucionalista, sigue siendo la cuestión que mayor número de páginas ha ocupado y la que más ha preocupado a los autores, hasta del punto de poder afirmarse que ninguno que haya tratado los grupos se ha resistido a dar su opinión sobre el particular ${ }^{12}$.

Sólo con ánimo de resumir las distintas posiciones que existen acerca de la naturaleza jurídica de los grupos y siguiendo, en buena medida, a Cillán García de Iturrospe ${ }^{13}$, se puede decir que las opiniones de los autores pueden ser adscritas a cuatro teorías.

En primer lugar, se encuentra la que puede calificarse de tradicional, que conceptúa a los grupos parlamentarios (léase, por su evidente similitud, sin duda, la expresión más amplia de grupos políticos para encajar los que constituyen objeto del presente trabajo) como asociaciones por su innegable carácter asociativo. Dentro de esta categoría general, no obstante, las opiniones divergen. Mientras lo que para unos son asociaciones no reconocidas y, por tanto, carentes de personalidad, para otros se trata de asociaciones-órganos, y hay quienes se limitan a afirmar que son asociaciones de derecho privado sin más; los hay que los califican de asociaciones de Derecho privado, pero investidas de funciones públicas por cuanto la ley fundamentalmente les atribuye tareas de relevancia constitucional y, no faltan tampoco quienes aseveran que se trata de asociaciones legales y permitidas, derivadas del ejercicio del derecho reconocido en el artículo 22 de la Constitución, aunque con ciertas peculiaridades.

\footnotetext{
${ }^{12}$ Una larga lista de autores y sus obras se pueden traer a colación en este momento, pero no parece que pueda aportar mucho, por lo que baste la remisión al trabajo de Martín Mª RAzQuin LizARRAGA, y Alejandro Sáiz ARnáiz, «Notas sobre la calificación jurídica de los grupos parlamentarios como asociaciones de Derecho privado», I Jornadas de Derecho Parlamentario, vol. II, Congreso de los Diputados, Madrid, 1985, pp. 1070-1076, que ya contiene, en buena parte, esta labor.

${ }^{13}$ Coro Cillán GarCía de IturRospe, «Los grupos parlamentarios», I Jornadas..., cit., pp. 11981200 .
} 
En segundo término, tenemos la que se podría denominar teoría del órgano, que sería aquella que concibe a los grupos políticos como órganos compuestos por un determinado número de parlamentarios (de cargos electos, podríamos indicar para abarcar los concejales) que operan en el ámbito parlamentario (o en el local, como sería nuestro caso) y que reflejan comúnmente una determinada política de los partidos, coaliciones, federaciones o agrupaciones electorales. Ahora bien, mientras para unos son órganos internos de las Cámaras o, más ampliamente, de la institución de que se trate, en cuanto instrumentos para el funcionamiento del Parlamento o de la institución local, si hablamos de grupos políticos locales, para otros son órganos del partido, por cuanto depende de éste y constituyen su expresión en la institución a que pertenezcan; y, en fin, también quienes los consideran a la vez órganos del partido en el ámbito del Parlamento esté o no así reconocido y que, por ello y a la vez, se trata de instrumentos del funcionamiento del Parlamentos mismo.

En tercer lugar, podemos situar la teoría de la institución, que se trataría de aquella que estima que los grupos parlamentarios son instituciones o sujetos sui generis de Derecho público o, más en concreto, de Derecho constitucional y que, por consiguiente, si por este aspecto pueden también considerarse asociaciones, que ejercen función pública o función constitucional, no se puede por esta sola actividad hacer que se derive la persona jurídica pública.

Y cabe aludir, por último, a la teoría de los grupos parlamentarios o, más ampliamente, políticos se diría aquí, que sostiene, tautológicamente, que los grupos parlamentarios son única y exclusivamente grupos parlamentarios.

Aunque, como se ha señalado, la teoría que más seguidores tiene y más fortuna ha hecho entre nosotros y, también, en general, en los países que funcionan de modo similar al nuestro es la primera de las enunciadas, es decir, la que considera a los grupos políticos asociaciones, creemos que es claramente insatisfactoria, pues, pese a los muchos elementos comunes que se pueden detectar con esta categoría, son también muchos e importantes los elementos que los separan de ella (piénsese, por ejemplo, como elemento diferenciador más importante, que las normas reguladoras de los grupos políticos niegan la vertiente negativa del derecho de asociación, esto es, el derecho a no asociarse o, desde la otra vertiente, que la norma jurídica impone la asociación).

A nuestro modo de ver, se está ante una realidad diferente, ante una categoría única, que no encuentra acomodo o explicación suficiente en 
ninguna de las anteriores, aún reconociendo las semejanzas que guarda con las otras, ya que nadie puede negar que sean una prolongación del partido en la institución de que se trate o que constituyan instrumentos que participan en la formación de la voluntad decisoria de la cámara o corporación local, en nuestro caso, o que tenga — como ya se ha subrayado-, elementos propios de las asociaciones. En definitiva, puede sostenerse que los grupos políticos son portadores de una naturaleza jurídica singular, dada la falta de complitud que producen las explicaciones que hasta el momento se han venido ofreciendo por la doctrina.

\section{NORMAS REGULADORAS}

Antes de adentrarnos en el Derecho material o sustantivo de la figura objeto de análisis, resulta necesario dar cuenta de las fuentes de derecho o, si se prefiere, del conjunto de normas que resulta de aplicación a los grupos políticos municipales, cuyo orden de prelación se encuentra establecido en el artículo 20 LBRL, después de lo manifestado en el Fundamento Jurídico $6^{\circ}$ de la Sentencia del Tribunal Constitucional 214/1989, de 21 de diciembre, que, como es conocido, declaró inconstitucional el artículo 5 LBRL en su redacción primitiva ${ }^{14}$, que establecía el orden de prelación de fuentes atendiendo a las distintas aspectos que integran la Administración local ${ }^{15}$.

\footnotetext{
${ }^{14}$ El Fundamento jurídico citado en texto, a los efectos que nos interesa, dice así: «... El precepto impugnado establece el orden de prelación de normas aplicables a las distintas materias que conciernen a la Administración Local, situando en primer lugar los contenidos en la propia Ley, que tiene así efectivamente una pretensión de superioridad ordinamental, que se hace explícita en su exposición de motivos. En cuanto que enumera las normas aplicables en una materia en la que la competencia legislativa está dividida entre el Estado y las Comunidades Autónomas, el precepto ha de ser entendido, en consecuencia, como una norma interpretativa de lo dispuesto en el bloque de la constitucionalidad, respecto de esta materia. Es esta naturaleza de norma meramente interpretativa, sin contenido material alguno, la que hace el precepto constitucionalmente ilegítimo...».

15 Algunos Reglamentos Orgánicos Municipales de los examinados prescriben con claridad el orden de fuentes en materia de organización y funcionamiento. Así, por ejemplo, el artículo 2 del Reglamento Orgánico del Ayuntamiento de La Coruña dice: La organización y funcionamiento interno del Ayuntamiento de La Coruña se ajustará al siguiente orden jerárquico de fuentes normativas:

a) La Ley 7/1985, del 2 de abril, reguladora de las Bases del Régimen Local.

b) La Ley 5/1997, del 22 de julio, de Administración Local de Galicia.

c) El Reglamento orgánico municipal.

d) El Real Decreto 2568/1986, de 28 de noviembre, por el que se aprueba el Reglamento de Organización, Funcionamiento y Régimen Jurídico de las Entidades Locales, para aquellas materias que resulte insuficiente la normativa establecida en el Reglamento Orgánico.

En términos similares se expresan, entro otros, los artículos 5 del Reglamento orgánico del Ayuntamiento de Gijón y 2 del Ayuntamiento de Málaga.
} 
En primer lugar, conforme al referido precepto, resulta de aplicación la norma cabecera de nuestro sistema local, esto es, la LBRL, reformada - en lo que ahora interesa-, por la Ley 11/1999, de 21 de abril, de modificación de la Ley 7/1985, de 2 de abril, Reguladora de las Bases de Régimen Local, y otras medidas para el desarrollo del gobierno local, en materia de tráfico, circulación de vehículos a motor y seguridad vial y en materia de aguas y, más recientemente, por la Ley 57/2003, de 16 de diciembre, de medidas para la modernización del gobierno local.

La primera versión de la LBRL sólo contenía, como se ha puesto de relieve, una fugaz alusión a los grupos políticos locales. En concreto, en el artículo 22.3, para los municipios, y en el artículo 32.3, para las provincias, se leía que «Todos los grupos políticos integrantes de la Corporación tendrán derecho a participar, mediante la presencia de Concejales (Diputados) pertenecientes a los mismos, en los órganos complementarios del Ayuntamiento (Diputación Provincial) que tengan por función el estudio, informe o consulta de los asuntos que hayan de ser sometidos a la decisión del Pleno». Es decir, la Ley no formalizaba su existencia, pero los preceptos que acaban de ser mencionados la daban por supuesta al reconocer su derecho a participar en los órganos que indican, que son las denominadas comisiones informativas. En todo caso, la regulación contenida en la Ley no es que fuera muy parca es que, simplemente, no existía.

La reforma de la LBRL, operada por una de las leyes que integraron el mal llamado Pacto Local ${ }^{16}$, la Ley 11/1999, de 21 de abril, reforzó a los grupos políticos, haciéndose eco — como ha escrito RIVERO YSERN ${ }^{17}$ - de la creciente importancia que presenta en el funcionamiento de las Corporaciones locales. Este reforzamiento de los grupos se hace patente, en primer lugar, cuando la nueva redacción que se da al artículo 73.3, contempla su existencia de manera obligatoria, al indicar que los corporativos deberán constituirse en grupos, y les reconoce el derecho a percibir una subvención con cargo a los presupuestos locales, que habrá de tener un componente fijo, igual para todos, y otro variable, en función del número de sus miembros, si bien, con una serie de limitaciones de las que se dará cuenta más adelante. Se advierte, en segundo término, en el nuevo artícu-

\footnotetext{
A estas disposiciones bien se las pudiera hacer la misma tacha que al precepto de la Ley básica que el máximo intérprete de la Constitución declaró inconstitucional.

${ }^{16}$ Sobre esta cuestión, vid. Antonio Calonge Velázquez, Alfredo Allué Buiza y Teodosio González del Teso, El Pacto Local de 1999. Medidas para el desarrollo del Gobierno Local, Comares, Granada, 2000.
}

${ }^{17}$ José Luis Rivero Ysern, Manual de Derecho Local, 4ª ed., Civitas, Madrid, 1999, p. 119. 
lo 46.2.e) cuando les garantizó su presencia efectiva en la parte de los Plenos dedicada a control de los órganos de gobierno, al posibilitar su participación en los ruegos, preguntas y mociones. Y se hace visible, por último, en el artículo 116, que prevé también la participación de todos ellos en la Comisión Especial de Cuentas.

En este mismo marco del denominado Pacto Local, la Ley Orgánica 8/1999, de 21 de abril, de modificación de la Ley Orgánica 5/1985, de 19 de junio, del Régimen Electoral General, con la nueva redacción que da al artículo 197.1.e) se reconoce también a los grupos políticos cuando les otorga el derecho a participar en las sesiones donde se discuta una moción de censura al expresar que «la mesa se limitará... a conceder la palabra durante un tiempo breve y si estuvieren presentes... a los portavoces de los grupos municipales...».

La Ley de medidas para la modernización del gobierno local (Ley 57/2003, de 16 de diciembre) ha añadido nuevas previsiones al artículo 73.3 LBRL que, podemos adelantar, tienen como objetivo principal castigar el transfuguismo y que, además, no resultan novedosas, pues ya se encontraban reflejadas en distintos reglamentos orgánicos municipales, si bien, ahora, su incorporación a la Ley básica conlleva su obligatoriedad a todas las Corporaciones locales. Una vez más el legislador estatal se ha limitado a dar acogida a la Ley lo que ya habían dispuesto con anterioridad los Entes locales. En concreto, ha introducido la figura de los miembros no adscritos de la Corporación, considerando como tales a aquellos que no se integren en el grupo político que constituya la formación electoral por la que fueron elegidos o que abandonen su grupo de procedencia; asimismo, ha regulado los derechos económicos y políticos de estos miembros no adscritos, afirmando que no podrán ser superiores a los que les hubiesen correspondido de permanecer en el grupo de procedencia, salvo en el caso de candidaturas presentadas como coalición electoral, cuando alguno de los partidos políticos que la integren decida abandonarla; y las consecuencias que conllevará el que la mayoría de los concejales de un grupo municipal abandonen la formación política que presentó la candidatura por la que concurrieron a las elecciones o sean expulsados de la misma, que no será otra que la de pasar a la situación de miembros no adscritos de la Corporación, pues los concejales que permanezcan en la citada formación política que concurrió a las elecciones serán los legítimos integrantes de dicho grupo político a todos los efectos.

El segundo escalón de normas que resultan de aplicación a los grupos políticos municipales está integrado por las Leyes de las Comunidades Autónomas, que, como ha dicho Belda Pérez-Pedrero, son las que están 
llamadas a tener el verdadero protagonismo en la materia ${ }^{18}$, por la sencilla razón de que es a éstas a las que corresponde, en virtud del sistema de distribución de competencias operado en materia de Administración local, la competencia para regular la organización interna de los municipios. Y, por lo que respecta al estatuto de los miembros de las corporaciones locales - capítulo en el que se inscribe el nuevo artículo 73.3 de la Ley básica, que reconoce la existencia obligatoria de los grupos políticos- compete también a las Comunidades Autónomas establecer una regulación complementaria o de desarrollo siempre que no vulneren ni contradigan lo dispuesto en la normativa básica.

Algunas Comunidades Autónomas han ejercido su competencia en esta materia y, con carácter general, en sus leyes reguladoras de la Administración local, han establecido una serie de previsiones aplicables a los grupos políticos municipales, cuya lectura permite observar que, básicamente, no se alejan mucho, como habrá ocasión de comprobar, de las disposiciones contenidas en el ROF, aunque se aprecia en ellas una regulación más completa y detallada que la llevada a cabo por el legislador estatal.

El tercer bloque de normas que están llamadas a tener un protagonismo en la disciplina de los grupos políticos son los Reglamentos Orgánicos de cada Corporación municipal, pues, conforme al pronunciamiento del Tribunal Constitucional anteriormente citado, el marco normativo por el que se ordena directamente y, en primer término, la organización de las Entidades locales queda constituido por las previsiones de la LBRL y de los Reglamentos Orgánicos de las Entidades Locales, que deberán respetar el espacio normativo que se reserve a la legislación autonómica de desarrollo en materia de organización municipal, que, no obstante, no será muy amplio debido a la regulación que de esta materia ha hecho el legislador básico estatal.

Y, finalmente, resulta de aplicación el ROF, cuya regulación de los grupos políticos locales constituyó en su momento una novedad en nuestro régimen local, al ser la primera vez que un texto de ámbito estatal y con rango de Decreto reconocía esta figura, que de hecho ya existía desde los inicios de las instituciones locales democráticas, por lo que poco menos que se limitó a recoger de manera sistemática lo que era práctica habitual en bastantes Ayuntamientos y Diputaciones provinciales.

Además de ofrecer — como más arriba se ha expuesto- un insuficiente concepto legal de esta figura político-jurídica, el ROF se limita prácticamente a atender tan solo dos cuestiones: por un lado, a disciplinar la

${ }^{18}$ «Los grupos políticos en Ayuntamientos....», cit., p. 254 
constitución de los grupos políticos (artículos 24, 25 y 26), es decir, a indicar la forma y los requisitos necesarios para que pueda entenderse que el grupo político ha nacido y, en consecuencia, puede desplegar su actividad; y, por otro, a imponer a cada Corporación local la obligación de que, en la medida de sus posibilidades, les dote de los medios materiales necesarios que les permitan cumplir las funciones que están llamados a desempeñar (artículos 27 y 28).

El Capítulo II del Título I del ROF, donde se contiene el régimen de los grupos políticos, se inicia con un precepto (artículo 23) que - además de definir a los grupos políticos- establece la obligatoriedad de su existencia en las Corporaciones locales al manifestar de manera clara e inequívoca - con carácter conminatorio, como ha dicho RoMero HeRnÁndeZ ${ }^{19}$ en su apartado primero que «Los miembros de las Corporaciones Locales... se constituirán en grupos»; no lo establece como una potestad discrecional de cada Entidad local, no dice «podrán constituirse», sino que lo impone, pues el tenor literal de este precepto es, como acabamos de transcribir, «constituirán», lo que indica una obligación.

Esta obligatoriedad en la constitución de grupos políticos fue criticada tempranamente por algún autor, que afirmó que esta norma carece de nivel para imponer al elegido un deber de esta índole ${ }^{20}$, si bien subsanaba esta tacha de ilegalidad al escribir más adelante: «Formalmente, se ha salvado el obstáculo dogmático cuando habiendo establecido el Reglamento Orgánico la obligada adscripción de cada concejal a un grupo, se regula con flexibilidad un grupo residual, el mixto, y se reconocen los derechos individuales de los que se integran en el mismo...» ${ }^{21}$.

La modificación que experimentó la LBRL por la Ley 11/1999 dotó de mayor rango normativo la obligación a que se viene haciendo referencia, pues, el artículo 73.3 LBRL tiene idéntico tenor literal al precepto reglamentario. En efecto, en el citado precepto legal puede leerse que «A los efectos de su actuación corporativa, los miembros de las Corporaciones locales se constituirán en grupos políticos», habiéndose añadido ahora que ello se hará «en la forma y con los derechos y obligaciones que se establezcan», esto es, reitera la obligatoriedad de la constitución de los grupos políticos en las Corporaciones locales conforme al estatuto que determinen las normas llamadas a complementar o desarrollar la normativa bási-

\footnotetext{
${ }^{19}$ F. Romero Hernández, Comentarios a la Ley Básica..., cit., p. 366.

${ }^{20}$ L. Morel OCAÑa, El régimen..., cit., p. 517.

${ }^{21}$ Ibidem, p. 518.
} 
ca estatal, que son, como sabemos, las leyes de las Comunidades Autónomas y el Reglamento Orgánico de cada Ayuntamiento.

No obstante, esta obligación impuesta por la legislación básica, a tenor del régimen de fuentes del derecho municipal, recordado por la Sentencia del Tribunal Constitucional varias veces mencionada, no tiene efectividad, ya que, como conocemos, son las leyes de las Comunidades Autónomas y los reglamentos internos de cada Entidad local los llamados a cumplir un papel de primera magnitud en esta materia ${ }^{22}$. Ahora bien, este mismo Tribunal, en su sentencia 30/1993, de 25 de enero, ha declarado que el legislador ha optado por la organización grupal del trabajo corporativo, estableciendo al efecto la obligatoria adscripción de todo concejal a un grupo municipal, configurando así un derecho-deber de los concejales a estar adscritos a un grupo político ${ }^{23}$.

Pero junto a la obligación de constituirse en grupos políticos, el artículo 23 ROF también contiene una prohibición o limitación —lógica, a todas luces - a los concejales, ya que dispone que «Nadie puede pertenecer simultáneamente a más de un grupo». Si, como hemos apuntado en un epígrafe anterior, uno de los elementos que caracterizan a los grupos políticos es que éstos constituyen un conjunto de autoridades que se reúnen por afinidad ideológica o, incluso, de otro tipo o naturaleza, es lógico que se disponga esta prohibición.

Finalmente, el Capítulo regulador de los grupos políticos se cierra con un precepto (artículo 29) que otorga a éstos las atribución de designar a aquellos de sus componentes que hayan de representarlos en todos los órganos colegiados integrados por miembros de la Corporación pertenecientes a los diversos grupos.

\section{RÉGIMEN JURÍDICO}

Analizadas las cuestiones generales anteriormente expuestas es hora de que nos sumerjamos en el régimen jurídico sustantivo de los grupos políticos municipales. El presente se divide, en aras a una mejor exposición,

\footnotetext{
${ }^{22}$ No parece compartir esta opinión José Manuel Canales AliEnde, «Gobierno local y democracia», Gobierno y Pacto Local, Ministerio de Administraciones Públicas-Ministerio de la Presidencia; Madrid, 1999, p. 45, quien, probablemente haciendo exclusivamente una interpretación literal de lo dispuesto en la legislación básica estatal, afirma que «los grupos políticos son de existencia obligatoria, debiendo pertenecer a ellos todos los concejales, no existiendo un numerus clausus mínimo de miembros dada la diversidad de Entes locales».
}

${ }^{23}$ Véase Fundamento Jurídico 5. 
en tres apartados: constitución, funcionamiento y medios. Es decir, en primer término, se estudiarán todas las cuestiones relativas al nacimiento a la vida político-jurídica de los grupos municipales; en segundo lugar, nos interrogaremos acerca de las funciones y atribuciones que pueden desempeñar y tienen legalmente establecidas los grupos municipales; $y$, por último, se pondrá el centro de atención en la cuestión de cuáles son los instrumentos materiales y personales de que pueden disponer para su funcionamiento.

Como se ha señalado en el epígrafe anterior, son las leyes autonómicas las llamadas a desempeñar el verdadero protagonismo en la materia, por lo que - además de exponer el Derecho estatal que es de aplicación directa a las Comunidades Autónomas que no hayan dispuesto nada sobre el particular, salvo lo que hayan previsto los reglamentos orgánicos de cada Ayuntamiento, y supletoria para las que, por el contrario, si han regulado- se tendrán muy presentes las leyes de Administración o Régimen local de las Comunidades Autónomas que, en virtud de las competencias estatutariamente asumidas sobre la materia, han contemplado disposiciones que disciplinan los grupos municipales.

\section{Constitución}

«Los grupos políticos se constituirán mediante escrito dirigido al Presidente y suscrito por todos sus integrantes, que se presentará en la Secretaría de la Corporación dentro de los cinco días hábiles siguientes a la constitución de la Corporación.

En el mismo escrito de constitución se hará constar la designación de Portavoz del grupo, pudiendo designarse también suplentes» (artículo 24 ROF).

Desde el punto de vista formal, los requisitos para la constitución de un grupo municipal se nos antojan sencillos, pues simplemente debe cumplimentarse un sencillo escrito suscrito por todos los miembros de la Corporación local que expresen su voluntad de constituirse en un grupo político, designando a un portavoz e, incluso, también un suplente. Este escrito se dirigirá a la Secretaría General de la Corporación dentro de los cinco días hábiles siguientes a aquel en que tuvo lugar la sesión constitutiva.

Ahora bien, como casi siempre, las cosas no son tan sencillas como parecen, pues el legislador estatal se ha dejado en el tintero, a nuestro juicio, algunas cuestiones sobre las que merece la pena que nos detengamos para tener un conocimiento más preciso y cabal de esta realidad. 


\subsection{Obligatoriedad}

En el régimen de los grupos existe un aspecto cuya determinación, como se ha dicho en páginas anteriores, no corresponde al legislador estatal, sino al autonómico y, en todo caso, a la propia Corporación municipal a través del correspondiente reglamento orgánico. Se trata de la obligatoriedad de constituir grupos municipales.

Las Leyes de las Comunidades Autónomas que contemplan este asunto no han optado, como parece lógico, por una solución uniforme.

Cataluña, que fue la primera Comunidad Autónoma que se ocupó de esta cuestión, dejó a la decisión del Pleno de cada Ayuntamiento acordar si se debía constituir o no grupos políticos, aunque impuso esta constitución en el caso de los municipios de población superior a veinte mil habitantes (artículo 48.1 de la Ley 8/1987, de 15 de abril, Municipal y de Régimen Local de Cataluña). El Derecho catalán actualmente vigente en esta materia, contenido en el Decreto Legislativo 2/2003, de 28 de abril, por el que se aprueba el Texto refundido de la Ley Municipal y de Régimen Local, establece en su artículo 50.1 el mismo mandato que el primitivo texto local, esto es, libertad de constitución de grupos municipales para los municipios con población inferior a veinte mil habitantes y, en cambio, obligatoriedad para los que superen esta cifra.

Por idéntica solución ha optado la Comunidad Autónoma de Aragón, quien en el artículo 111.1 de la Ley 7/1999, de 9 de abril, de Administración Local de Aragón, establece que «... el Pleno podrá acordar la creación de grupos políticos, cuya constitución será obligada en los municipios de más de 5.000 habitantes».

Otras Comunidades Autónomas han optado, en cambio, por la obligatoriedad general, esto es, han diseñado como elemento organizativo de los Plenos municipales los grupos políticos. A este respecto, Galicia, utilizando la misma dicción literal que el legislador básico estatal, obliga a los concejales de sus Ayuntamientos a que se constituyan en grupos políticos. En efecto, el artículo 74 de la Ley 5/1997, de 22 de julio, de Administración Local de Galicia, dispone en su primer apartado que «Los concejales, a los efectos de su actuación corporativa, se constituirán en grupos...» y no sólo eso pues en el apartado cuarto del citado precepto prevé la existencia de un grupo mixto para todos aquellos miembros de la Corporación local que no se integren o no puedan integrarse en un grupo político. La Comunidad Autónoma de Canarias, por su parte, también ha establecido la obligatoriedad de los grupos políticos en los Ayuntamientos de su territo- 
rio; cuando, de manera indubitada, ha señalado la obligación de todo concejal de adscribirse a un grupo municipal ya ha previsto, consecuentemente, la existencia de un grupo mixto para todos aquellos concejales que no queden integrados en un grupo político (artículo 73 de la Ley 14/1990, de 26 de julio, de Régimen Jurídico de las Administraciones Públicas Canarias.

Y, en fin, hay Comunidades que han preferido remitir esta cuestión a la autoorganización de los Ayuntamientos, como es el caso de las Comunidad Autónomas de la Región de Murcia y de Madrid. Aunque esta última haya dispuesto en el artículo 32.1 de la Ley 2/2003, de 11 de marzo, de Administración Local, que los concejales «actuarán» corporativamente mediante la constitución de grupos políticos, lo cierto es que a continuación se remite a lo que disponga el reglamento orgánico municipal, lo que no puede interpretarse, sino como que el legislador madrileño ha dejado libertad a los Ayuntamientos que componen la Comunidad Autónoma para que decidan la mejor manera de organizarse y funcionar.

Surge la duda, no obstante, de la compatibilidad entre la obligación de constituir grupos políticos que establece, con carácter básico, el artículo 73.3 de la Ley 7/1985, de 2 de abril, en la redacción dada por la Ley 11/1999, de 21 de abril, y las leyes autonómicas que, por el contrario, han dejado libertad a todos o a algunos Ayuntamientos para la constitución de grupos municipales. Lo cierto es que, atendiendo al orden de prelación de fuentes en la materia que tratamos señalada por al Sentencia del Tribunal Constitucional 214/1989, de 21 de diciembre, se debe concluir que todos los Ayuntamientos o, mejor expresado, todos los Plenos municipales deberían configurarse y funcionar a través de los grupos políticos, pero la realidad, como todos sabemos, no es ésta y las leyes autonómicas no han sido impugnadas en este punto.

Los reglamentos orgánicos municipales que se ha tenido ocasión de examinar ${ }^{24}$ han determinado la obligatoriedad de constitución de los grupos municipales en el seno del Ayuntamiento con fórmulas en unos casos facultativas y en otros imperativas. Las normas de autoorganización de los Ayuntamientos de Salamanca y Valladolid aluden a la constitución de los grupos municipales en términos facultativos. El artículo 34.1 del reglamento orgánico del primero y el artículo 25.1 de igual disposición del segundo establecen en términos facultativos que «Los concejales... podrán constituirse en grupo municipal», esto es, no lo ordena, sino que lo

\footnotetext{
${ }^{24}$ Estos reglamentos son los de los Ayuntamientos de Calviá, Cartagena, Gijón, Granada, La Coruña, Málaga, Salamanca, Toledo, Valencia, Valladolid, Vitoria y Zaragoza.
} 
posibilita, aunque, a la vista de toda la regulación que contienen sobre esta figura, debemos concluir que los citados Ayuntamientos se han organizado por grupos municipales, ya que determinan, entre otros, extremos el número mínimo para que puedan constituir, establecen limitaciones a la libertad de constitución de los grupos y, en fin, crean el grupo mixto en el que deberán encuadrarse aquellos concejales que no se hayan adscrito o no puedan hacerlo por imperativo legal a un grupo municipal. El resto de reglamentos que hemos tenido presentes son, sin embargo, imperativos, pues con ese carácter declaran que todos y cada uno de los concejales se constituirán en grupos políticos ${ }^{25} \mathrm{o}$, en fin, utilizan la misma fórmula que la empleada por el ROF, supuesto este en el que se encuentra el reglamento orgánico granadino en cuyo artículo 178.1 se dispone que «Los miembros del Ayuntamiento, a efectos de su actuación corporativa, se constituirá en grupos».

\subsection{Número mínimo}

Un aspecto especialmente vidrioso lo constituye la fijación del número mínimo que se precisa para constituir grupo político, pues por la propia dicción del término y de las definiciones que del mismo se han ofrecido estamos hablando de un conjunto de personas o, al menos, de dos o más concejales que se unen para actuar en el seno de la Corporación.

El legislador estatal, con buen criterio, no se ha pronunciado sobre esta cuestión. Sí lo han hecho, en cambio, la mayoría de las Comunidades Autónomas que han regulado los grupos políticos.

No ofrece duda que el grupo mixto, que - como algún autor ha dicho de manera acertada - es el «no grupo» ${ }^{26}$, puede constituirse válidamente con un sólo miembro por la sencilla razón de que al haberse establecido de modo obligatorio la constitución de los grupos políticos, es lógico que aquellos que no quieran o no puedan (porque no cumplen los requisitos normativamente establecidos) integrarse en uno de los grupos constituidos puedan formar o integrar el grupo mixto si es un derecho-deber de los concejales estar adscritos a uno de los grupos, según ha señalado el Tribunal Supremo en su sentencia de 26 de septiembre de $2002^{27}$, no permitir la

\footnotetext{
${ }^{25}$ Vid., por todos, artículo 6.1 del Reglamento orgánico del Ayuntamiento de Vitoria.

${ }^{26} \mathrm{M}^{\mathrm{a}}$ Jesús Larios Paterna, «El grupo mixto en los Parlamentos de las Comunidades Autónomas», $R C G, \mathrm{n}^{\circ} 36,1995$, p. 61.

${ }^{27}$ RJ 2002/913, Ponente D. Nicolás Maurandi Guillén.
} 
constitución de este grupo con un sólo miembro supondría que el concejal que se pueda encontrar en tal situación queda en la situación de no adscrito, si no se le están impidiendo desarrollar su función representativa en las mismas condiciones que el resto de los concejales, con vulneración, por tanto, del artículo 23.2 de la Constitución. En definitiva, el grupo mixto es, como ha señalado la mayoría de la doctrina constitucionalista ${ }^{28}$, un grupo de cierre del sistema, por lo que la propia naturaleza del mismo obliga a su existencia, aunque cuente con un sólo miembro.

Y, entendemos, asimismo, que ante el silencio del legislador nada impide la constitución de un grupo político con un solo miembro (por ser el único elegido de su lista electoral), porque la práctica así lo confirma y el único argumento que impide hablar de grupo integrado por un cargo es, como ha dicho BeLda Pérez-Pedrero, «el sentido literal de la palabra» 29 y porque, como también ha manifestado BERNAL RIOBóo con apoyo en la Sentencia del Tribunal Supremo anteriormente citada ${ }^{30}$, si los grupos son la traducción de las listas electorales, no cabe negar sustantividad propia a la lista elegida por el hecho de que la misma conste de un concejal, obligándole, en ausencia de norma que coarte esta libertad a integrarse en el grupo mixto.

Entrando ya en el panorama que ofrece el ordenamiento autonómico probablemente sean las Comunidades Autónomas de Cataluña y Aragón las que, a nuestro juicio, contienen una regulación más respetuosa con la autonomía municipal, lo que no significa que las otras Comunidades Autónomas que también han disciplinado este aspecto con fijación de un número mínimo necesario para la constitución de un grupo político hayan quebrantado la autonomía local constitucionalmente garantizada. Aragón ha dado libertad a cada Ayuntamiento al señalar el apartado $3^{\circ}$ del artículo 111 de su Ley de Administración Local, que cada reglamento orgánico podrá exigir un número mínimo para la constitución del grupo político, en cuyo caso obliga a regular, lógicamente, el grupo mixto. Cataluña, por su parte, también remite la regulación de este punto a cada Ayuntamiento pues el artículo 50.2 del Texto refundido dispone que «Si ningún acuerdo del pleno regula lo contrario...» por cada lista puede formarse un grupo municipal; es decir, si el propio Ayuntamiento no señala un núme-

\footnotetext{
${ }^{28}$ Véase, por todos, A. SAIZ ARNÁIZ, «El carácter obligatorio de la pertenencia a un grupo parlamentario: el grupo mixto y las agrupaciones en el Congreso de los Diputados», $R C G, \mathrm{n}^{\circ} 13,1988$, p. 99.

29 Belda Pérez-Pedrero, E., «Los grupos políticos...», cit., p. 270.

${ }^{30}$ La Redacción de El Consultor, Manual..., p. 170.
} 
ro mínimo el legislador autonómico prevé que el grupo político se pueda constituir con un solo miembro cuando la lista que ha concurrido a las elecciones haya obtenido un electo y aún se explicita más en el apartado siguiente del precepto citado al decir que «Sólo el concejal.... de una misma lista electoral puede constituir grupo municipal», esto es, cuando el elegido de una lista electoral sea uno, éste tiene derecho a constituir grupo municipal.

Galicia y Canarias, en cambio, no han dejado ámbito de libertad alguno a los Ayuntamientos de sus territorios, pues, respectivamente, exigen un mínimo de 2 (artículo 74.4 de la Ley gallega) y 3 concejales (artículo 73 de la Ley canaria) para poder constituir grupo político, obligando, de no disponer de ese número, a formar parte del grupo mixto a los miembros de las Corporaciones locales que pertenezca a partidos, coaliciones, federaciones o agrupaciones electorales que no hubieran obtenido esa representación mínima. Desde el punto de vista político, no parece lo más acertado, en nuestra opinión, establecer un número mínimo para poder constituir grupo político, pues el principio del pluralismo político demanda que cada lista electoral que haya obtenido representación en la institución municipal pueda constituir su cauce de expresión, esto es, grupo municipal, ya que debe reflejarse con la mayor exactitud posible lo que los ciudadanos han manifestado a través de sus votos.

La Región de Murcia ha optado también por imponer en sus Ayuntamientos un número mínimo necesario para poder constituir grupo político. Su regulación se sirve de dos criterios para determinar ese número necesario. Un primer criterio, que expresa en estrictos términos numéricos los concejales que se precisan para constituir grupo político, aparece en el apartado $1^{\circ}$ del artículo 27 de la Ley de Administración Local según el cual «Los miembros de la Corporación, en número no inferior a dos...»; el segundo criterio, que expresa ese mínimo necesario en términos porcentuales, se contempla en el apartado $2^{\circ}$ del mismo precepto legal al señalar que también podrán constituir grupo político los concejales de aquellos partidos, coaliciones, federaciones o agrupaciones electorales que hubieran obtenido, al menos, el ocho por ciento de los votos emitidos en el conjunto del municipio.

La Comunidad Autónoma de Madrid, por último, nada dice sobre el particular, salvo la remisión genérica que hace en el primer párrafo del artículo 32 de su Ley de Administración Local a la legislación local y al reglamento orgánico del municipio, por lo que baste tener presente lo expresado al principio de este apartado. 
Los reglamentos orgánicos municipales que han sido consultados para la realización del presente estudio se han decantado, de manera mayoritaria, por establecer expresamente un número mínimo para constituir grupo municipal, aunque también los hay que no se han pronunciado sobre este aspecto, sin perjuicio de que de su contenido se desprenda que basta que un solo miembro es bastante para constituir grupo municipal. El reglamento orgánico del Ayuntamiento de Cartagena, por ejemplo, dispone que «Todo partido político o coalición con representación en el Ayuntamiento tiene derecho a constituir grupo político municipal» o, más expresivamente, el reglamento del Ayuntamiento de Granada, cuyo artículo 178.3 manifiesta que «... los grupos políticos se constituirán, cualquiera que sea su número, mediante corporativos que pertenezcan a una misma lista electoral».

\subsection{Limitaciones a la libertad de constitución}

La libertad que legislador estatal ha dejado a los miembros de las Corporaciones locales para que se constituyan en grupos políticos es, sin ningún género de duda, amplia, hasta el punto de que la única limitación expresa, recogida en el artículo $23.2 \mathrm{ROF}$, reside en que ningún miembro del Ayuntamiento puede pertenecer simultáneamente a más de un grupo. Y dependiendo de la interpretación que demos podemos encontrar otra limitación a la libertad de constituir grupos políticos en el artículo 24.1 del mismo cuerpo legal, que establece el plazo de cinco días hábiles siguientes a la constitución de la Corporación para poder constituir grupo, es decir, establece una limitación temporal, si bien sobre esta cuestión se volverá más adelante. Nada ha previsto sobre otras prohibiciones habituales en la materia tales como que no puede constituirse grupo político separado por miembros pertenecientes a un mismo partido o formar grupo político separado los miembros que, al tiempo de las elecciones, pertenecieran a formaciones políticas que no se hayan enfrentado ante el electorado. Tampoco se han previsto límites temporales al cambio de un grupo político a otro. En fin, serán los reglamentos orgánicos de las Corporaciones locales los que deberán, si así les parece conveniente, regular estas cuestiones, sin perjuicio de que lo hayan previsto ya las leyes autonómicas, cuyo contenido, como nos consta, debe ser respetados por aquéllos.

Algunas Comunidades Autónomas, a la hora de regular esta realidad que son los grupos políticos, han establecido, en efecto, algunas limitaciones a esa inicial libertad de constitución, todas lógicas en nuestra opinión pues se derivan de la propia naturaleza del sistema. 
Las leyes de las Comunidades Autónomas comienzan reiterando la limitación expresa recogida en la legislación estatal a la que nos acabamos de referir, es decir, que ningún concejal podrá pertenecer simultáneamente a más de un grupo político y, además, todas, prácticamente, utilizan, incluso, la dicción que emplea el legislador estatal ${ }^{31}$. Únicamente Cataluña tiene establecido en el artículo 50.3 del Decreto legislativo 2/2003, de 28 de abril, que «Sólo el concejal o los concejales de una misma lista electoral pueden constituir grupo municipal», lo que, a nuestro parecer, debe entenderse asimismo como una limitación a los miembros de las Corporaciones locales a que puedan pertenecer, a la vez, a más de un grupo político.

Otra restricción común establecida por los legisladores autonómicos es, también, que debe haber una correspondencia entre lista electoral y grupo político, esto es, que los concejales elegidos por una lista electoral deberán integrarse necesariamente en el grupo que corresponda a la candidatura en el que resultaron elegidos. La acogen para sus respectivos territorios los artículos 50.3 de la de Cataluña, 30.1 de la de Murcia, 74.5 de la de Galicia, 73 de las de las Canarias, 111.2 de la de Aragón y 32.2 de la de Madrid, aunque, en ese caso, con dicciones diferentes.

Con igual generalidad se ha previsto que en el caso de que uno o varios concejales dejen de pertenecer al grupo político constituido por la candidatura en la que resultaron elegidos, no podrán pasar a pertenecer al grupo de otro partido, federación, coalición o agrupación electoral que concurriere a las elecciones o formar grupo político propio. La solución que para esos supuestos han previsto los legisladores autonómicos es que se integren en el grupo mixto o que queden, para lo que resta de mandato, como concejales no adscritos. Por la primera opción se han decantado los legisladores murciano, gallego y canario (artículos 30.1, 76.1 y 73 in fine, de sus respectivas leyes). Han apostado, en cambio, por la segunda las Comunidades Autónomas de Cataluña, Aragón y Madrid que, luchando contra el transfuguismo político, impiden que estos concejales puedan beneficiarse de su pertenencia a un grupo político, siquiera sea el mixto. Madrid, como ya hiciera con anterioridad el legislador catalán, subraya que el concejal no adscrito tendrá los mismos derechos que individualmente le correspondan como miembro de la Corporación pero no los derivados con carácter exclusivo de su pertenencia a un grupo político. Tan loable propósito no impide las dudas acerca de la validez de la figura del

\footnotetext{
${ }^{31}$ Véanse los artículos 30.1 de la Ley murciana, 74.3 de la Ley gallega, 111.2 de la Ley aragonesa, 73 de la Ley canaria y 32.2 de la Ley madrileña.
} 
concejal no adscrito cuando, como hemos visto, es el propio legislador el que obliga a todos los Ayuntamientos o, mejor dicho, a sus Plenos a funcionar por grupos. Opinamos que tal figura no es conforme a Derecho precisamente por la decisión del legislador de la obligatoriedad de constitución de grupos políticos en las instituciones municipales. Como ha señalado el Tribunal Constitucional, estamos ante un derecho-deber y, en consecuencia, no se puede negar a ningún miembro de la Corporación local su inclusión en un grupo, el mixto, que es de obligatoria existencia, precisamente para no impedir que un concejal pueda actuar corporativamente desde un grupo político, aunque sea tan sui generis como éste, ya que de otro modo se le estaría vulnerando su derecho. Ahora bien, esto que decimos ya no tiene sentido mantenerlo después de que el legislador básico, en la reciente modificación de la LBRL, haya decidido reconocer esta figura hasta el punto de que obliga a que queden en la situación de no adscritos aquellos concejales que no se integren en el grupo político que constituya la formación electoral por la que fueron elegidos o que abandonen su grupo de procedencia.

Los reglamentos orgánicos municipales a que se viene haciendo alusión contienen diversas disposiciones que limitan la libertad de constitución, todas en absoluta sintonía con lo establecido en las leyes autonómicas respectivas que, por otra parte, no deja de ser — mutatis mutandi- lo dispuesto en los Reglamentos del Congreso y del Senado. Así, contemplan la limitación genérica de que nadie podrá pertenecer simultáneamente a más de un grupo, señalan que los concejales que abandonen o sean expulsados del grupo que ayudaron a constituir deberán pasar al grupo mixto o, incluso, quedar en la condición de no adscritos o no inscritos, y prevén que no podrán constituir grupo, por separado, los concejales que pertenezcan a una misma lista electoral o que, en las elecciones, no se hayan enfrentado al electorado, etc. ${ }^{32}$.

\footnotetext{
${ }^{32}$ Los artículos 34 y 36 del reglamento orgánico del Ayuntamiento de Salamanca y los artículos 14 y 15 del de Valencia son muy expresivos y comprensivos de lo que decimos. En ellos puede leerse lo siguiente:

En ningún caso pueden constituir grupo municipal separado los concejales que hayan concurrido electoralmente en un mismo partido o coalición (artículo 34.2), ni aquellos que pertenezcan a formaciones políticas que, en las elecciones, no se hayan enfrentado al electorado (artículo 14.2).

Ningún concejal podrá formar parte de más de un grupo municipal (artículo 34.3 y 15.3)

Los concejales que causen baja en el grupo municipal en el que estuvieron integrados adquieren la condición de no adscritos (artículo 36.1)

Durante el mandato de la Corporación ningún concejal podrá integrarse en un grupo distintos de aquél en el que lo haga inicialmente (artículo 15.3).
} 


\subsection{Procedimiento}

Un aspecto de menor relevancia, pero del que no se puede prescindir es el relativo el procedimiento que debe seguirse para la constitución de un grupo político en una Corporación local o, si se prefiere, los requisitos formales que deben cumplimentarse para que ese conjunto de miembros de la Corporación ideológicamente afines se constituyan en un grupo político, a efectos de su actuación corporativa.

Cuatros son los aspectos que se abordarán en las páginas que siguen con la finalidad de conocer la cuestión principal que nos ocupa ahora y que, como habrá ocasión de contemplar, plantean algunas dificultades jurídicas dignas de ser resaltadas.

\section{A) Solicitud}

A través del artículo 24.1 ROF, el legislador estatal ha dejado establecido que «Los grupos políticos se constituirán mediante escrito dirigido al Presidente y suscrito por todos sus integrantes...». Es decir, que el primer requisito formal que deben cumplir aquellos concejales que tengan la voluntad de formar un grupo político es presentar un sencillo escrito, suscrito por todos, en el que manifiesten esa preferencia de unirse para actuar corporativamente.

Los legisladores autonómicos también han iniciado — de manera mayoritaria - la regulación del procedimiento de constitución de un grupo político con la exigencia de la presentación de un escrito que, firmado por todos los integrantes, sea expresión de su voluntad de conformar un grupo municipal. Así se dispone en los artículos 27.3 de la Ley murciana, 75 de la gallega, 73 de la canaria y 111.4 de la aragonesa. En la Comunidad Autónoma de Cataluña se requiere un escrito, pero no suscrito por todos los integrantes o, mejor dicho, no colectivo, sino individual, ya que el artículo 50.4 del Texto refundido de la Ley municipal y régimen local, demanda con toda claridad que cada concejal presente una declaración firmada donde tiene que expresar el grupo municipal al cual desea ser adscrito. Mención especial merece la Ley de Murcia que no sólo exige este escrito colectivo de iniciación para la constitución de un grupo político, sino también para su modificación, previsión esta que no ha realizado ningún otro legislador, aunque debe entenderse requerido, al menos, para todo concejal que abandone o sea separado del grupo municipal que ayudó a constituir y, si ello fuera normativamente posible, forme parte de otro o pase a formar parte del grupo mixto. 
Los reglamentos orgánicos municipales a los que se viene haciendo referencia, como no podía ser de otra forma, también prevén la iniciación del procedimiento de constitución de un grupo municipal mediante un sencillo escrito suscrito por todos sus integrantes, firmado por todos o cualquier otra expresión similar reveladora de la voluntad de aquéllos de formar un grupo político. Con este tenor se pronuncian los artículos 66.1 del Reglamento orgánico del Ayuntamiento de Calviá, 16.1 del de Cartagena, 27 del de Gijón, 7 de la Coruña, etc.

La Comunidad Autónoma de Madrid no ha dispuesto nada sobre el particular, aunque la remisión que ha hecho en el apartado 1 del artículo 32 de su Ley de Administración Local a la legislación sobre régimen local y al reglamento orgánico municipal, determina que debemos atender, en primer término, a la norma de autoorganización de cada municipio para conocer cómo se inicia el procedimiento de constitución de un grupo municipal y, si esta no dispone nada, al ROF, pues, como sabemos, es Derecho supletorio que resulta de aplicación en el caso de que el Derecho autonómico nada disponga sobre el particular, si bien en este caso resulta de aplicación por propia decisión del legislador autonómico al hacer expresa remisión a aquél.

Este escrito se presentará - dice el artículo 24.1 ROF- en la Secretaría General de la Corporación. Algunas Comunidades Autónomas han optado en sus legislaciones por este mismo mandato (artículos 27.3 y 75 de las Leyes de Administración Local de Murcia y Galicia, respectivamente). Pero, otras — de manera más acertada, en nuestra opinión- han decidido que dicho escrito debe ser presentado ante la alcaldía (artículo 50.4 del Texto refundido de Cataluña), el Alcalde (artículo 73 de la Ley canaria) o el Presidente de la Corporación (artículo 111.4 de la ley de Aragón). Los reglamentos órgánicos han sido, quizás, más precisos, pues algunos de ellos han determinado que será dirigido a la Alcaldía y presentado en la Secretaría General (artículo 27 del reglamento orgánico del Ayuntamiento de Gijón). No obstante, esta cuestión, a nuestro parecer, carece de trascendencia jurídica, ya que nada impide que, a tenor de lo dispuesto en las leyes generales administrativas, este escrito sea presentado en el registro general de la Corporación y, en consecuencia, surta los mismos efectos que si hubiera sido presentado en el órgano administrativo que expresamente señala la norma.

\section{B) Contenido}

El contenido del escrito de iniciación del procedimiento de constitución de un grupo político también está determinado, al menos, en su mínimo 
por el legislador. En efecto, el estatal en el artículo 24 ROF tantas veces mencionado y, en concreto, en su apartado 2 indica que, además de dar cuenta de los integrantes del grupo municipal, se hará constar la designación de Portavoz del grupo, pudiendo designarse también suplentes. De los legisladores autonómicos, los más se han limitado a ordenar lo que el legislador estatal (artículos 29.1 de la Ley murciana y 75.2 de la gallega) o, simplemente, a no decir nada (artículos 50 del Texto refundido catalán y 32 de la Ley de Administración Local de Madrid). Sólo el legislador canario y el aragonés han especificado que en este escrito sus integrantes expresarán su voluntad de formar parte del grupo, su denominación, los nombres de todos sus miembros, el nombre de su Portavoz y el de los concejales que en su ausencia pueden sustituirle (artículo 73 de la Ley de Régimen Jurídico de las Administraciones Públicas de Canarias y 114 de la Ley de Aragón).

Los reglamentos orgánicos municipales, como era de esperar, tienen contenidos diversos, pero en el mismo tenor - como, asimismo, no podía ser de otra manera - de lo dispuesto por el legislador autonómico respectivo. Esto es, algunos han sido parcos disponiendo exclusivamente que los citados escritos contendrán la designación del Portavoz y de sus suplentes ${ }^{33}$, y otros, en cambio, han sido más prolijos obligando a que conste la denominación del grupo, el nombre de todos los integrantes, de su portavoz y de los concejales que, en caso de ausencia, puedan sustituirle ${ }^{34}$.

Ningún problema jurídico parece plantearse, en nuestra opinión, con este escrito, aunque algún autor ha puesto de relieve, en relación a la designación del Portavoz, la dificultad de lograr la unanimidad, que, a su juicio, exige el artículo $20.4 \mathrm{ROF}$, en el grupo mixto donde por sus especiales características sería suficiente la mayoría ${ }^{35}$. No creemos que el artículo 24 ROF obligue, ni explícita ni implícitamente, a que el Portavoz del grupo municipal sea designado por una determinada mayoría; es más, pensamos que, lógicamente, el legislador no se ha pronunciado al respecto porque sería inmiscuirse en el funcionamiento interno de lo que constituye un conjunto de miembros del Ayuntamiento que se unen para actuar mejor y más eficazmente en la vida corporativa ${ }^{36}$. Sin duda, está claro que la legis-

\footnotetext{
${ }^{33}$ Véase, por ejemplo, los artículos 27 del reglamento gijonés, 179.2 del granadino, 7 del coruñes y 66.1 del de Calviá.

${ }^{34}$ Entre otros, pueden verse los artículos 16.2 del reglamento cartagenero, 25 del malagueño, 35.2 del salmantino y 26.2 del vallisoletano.

35 La Redacción de El Consultor, Manual..., cit., p. 171.

${ }^{36}$ El reglamento orgánico del Ayuntamiento de Zaragoza señala, de manera expresa, a propósito
} 
lación de régimen local no contiene previsión alguna sobre el sistema de designación de portavoz del grupo ${ }^{37}$. Sólo, que conozcamos, pero en otro aspecto distinto al que ahora se trata, la Ley de Régimen Local de la Región de Murcia, en su artículo 29.2, ha determinado cuáles son las facultades que competen a esta figura al señalar que son las de coordinación y representación del grupo político.

Con carácter general, los reglamentos orgánicos municipales no han regulado esta cuestión ${ }^{38}$, aunque han habido algunos que sí contienen disposiciones relativas a la portavocía del grupo mixto. Así, por ejemplo, el reglamento del Ayuntamiento de Salamanca, en su artículo 35.3, establece que el grupo mixto establecerá un turno rotatorio para el desempeño de la función de portavoz, turno que será proporcional a la composición del grupo, y el artículo 26.3 del reglamento del Ayuntamiento de Valladolid contiene una previsión similar.

\section{C) Plazo}

Los miembros de la Corporación que deseen constituir un grupo político disponen de un plazo para formalizar tal voluntad. En el Derecho estatal y, en concreto, el tantas veces mencionado artículo 24.1 ROF fija un plazo de cinco días hábiles, después de la sesión constitutiva de la Corporación, para que los concejales presenten el escrito de constitución, estableciendo así el criterio, como ha puesto de relieve Morell Ocaña, de que sólo deberían formarse grupos en el instante inicial del mandato de los concejales, no después ${ }^{39}$. Romero HERnÁndez ha escrito que se trata de un plazo perentorio que en la práctica se ve incumplido, por lo que se pronuncia porque los reglamentos orgánicos municipales aprovechen su situación peculiar en el sistema normativo para permitir que ese plazo inicial pueda en algunos casos excepcionarse ${ }^{40}$.

\footnotetext{
de lo que se afirma en el texto justamente que «los grupos municipales gozarán de total autonomía en cuanto a su organización interna» (artículo 28).

37 Mariano BAEnA DEl AlCÁZAR, «El control del gobierno local. Los grupos de oposición tras el pacto local», Nuevas perspectivas del Régimen Local. Estudios en homenaje al Profesor José María Boquera Oliver, coords. José María Baño León, Juan Climent Barberá, Tirant lo blanch, Valencia, 2002, p. 585, ante la ausencia de regulación escribe que «Es de entender que la designación se hará según reglas y procedimiento democráticos, pero no se detalla si se exige mayoría cualificada».

${ }^{38}$ El reglamento orgánico del Ayuntamiento de Valencia es una excepción a esta regla general, aunque sólo para la modificación de la designación del portavoz y de suplentes, ya que su artículo 17.2 exige mayoría absoluta del grupo para realizarla.

${ }^{39}$ El régimen local..., cit., p. 519.

40 «Los grupos políticos...», cit., pp. 238 у 239.
} 
En esta materia de organización de las Entidades locales — no es preciso recordarlo- no es el Derecho estatal, salvo el básico, el que resulta de preferente aplicación, sino que lo es el autonómico y la propia norma de autoorganización municipal, por este orden.

Algunos legisladores autonómicos han tomado la misma decisión que el estatal y, por ello, han dispuesto que el escrito en el que se formalice el grupo municipal se presentará dentro de los cinco días hábiles siguientes a la constitución de la Corporación (artículos 73 de la Ley de Régimen Jurídico de las Administraciones Públicas de Canarias y 75.1 de la Ley de Administración Local de Galicia). Otros, por el contrario - y con mayor sentido de la realidad, en nuestra opinión- han establecido plazos más amplios que el determinado por la normativa estatal. Así, Cataluña — para los municipios de más de veinte mil habitantes, que son los que, como sabemos, de manera obligatoria deben constituir en su seno grupos municipales - ha señalado que las declaraciones de los concejales que expresen el grupo municipal al que deseen ser adscritos deberán presentarse a la alcaldía antes del primer pleno ordinario después de la sesión constitutiva del Ayuntamiento; y para los demás municipios ha remitido a cada Ayuntamiento la decisión de establecer el plazo que considere más conveniente para la constitución de grupos municipales en el mismo acuerdo en que decida organizarse conforme a tales grupos (artículo 50.4 del Texto refundido de régimen local y municipal). Aragón, que tiene una regulación en este extremo similar a la que se acaba de ver, también ha dispuesto, en el artículo 111.4 de su Ley de Administración Local, idéntico plazo que el de la normativa catalana, esto es, antes del primer pleno ordinario después de la Constitución de la Corporación.

Las Comunidades Autónomas de Murcia y Madrid en sus correspondientes leyes reguladoras de la materia local no se han pronunciado sobre este particular, lo que conlleva la aplicación del ROF, que actúa, como ya se ha resaltado en diversas ocasiones, como derecho supletorio ante el silencio del legislador autonómico en la materia que se trata y, ello, siempre que los reglamentos orgánicos municipales no dispongan nada sobre el particular. En el caso de la Comunidad madrileña, además, es la propia ley la que remite de manera expresa a la legislación estatal de régimen local, como ya hemos advertido con anterioridad.

No debemos olvidar las normas que, casi, a la postre resultan de preferente aplicación, es decir, los reglamentos orgánicos municipales. Pues bien, las normas orgánicas municipales que se han tenido presentes en la confección de este trabajo se pronuncian, de manera prácticamente unánime, por establecer el riguroso plazo otorgado por el autor del ROF y, por 
ello, nos encontramos preceptos con el siguiente tenor: «dentro de los cinco días hábiles siguientes a la constitución de la Corporación...». Los Ayuntamientos de las ciudades que riegan el Tormes y el Pisuerga que se ha visto han sido más generosos que sus homólogos, ya que han dado a sus corporativos un plazo de quince días desde la sesión constitutiva de la Corporación para presentar ante la Secretaría General el escrito de constitución de los grupos municipales (artículos 35.1 del Ayuntamiento salmantino y 26.1 del reglamento orgánico vallisoletano).

Antes de poner fin a este apartado, debe subrayarse que el plazo que las normas otorgan para constituir grupo municipal lo es de caducidad, transcurrido el cual ya no es posible la formación de nuevos grupos municipales. Alcanzamos esta conclusión por deducción de lo que establece la normativa reguladora de la materia $\mathrm{y}$, sobre todo, de las disposiciones reguladoras de las limitaciones que se han establecido a la libertad de constitución de los grupos municipales, pues es muy frecuente, como se ha visto en páginas anteriores, las previsiones que impiden formar un grupo municipal a aquellos que se separan o son expulsados de aquel que se formó con la lista electoral por la que resultaron elegidos, obligándoles a integrarse en el grupo mixto, si ya estuviera constituido o a constituirlo por este hecho, o, incluso, a quedar en la situación de concejal no adscrito.

\section{D) Publicidad}

El artículo 26 ROF es del siguiente tenor literal:

«De la constitución de los grupos políticos y de sus integrantes y portavoces, el Presidente dará cuenta al Pleno en la primera sesión que se celebre tras cumplirse el plazo previsto en el número 1 del artículo anterior».

Este precepto, como se observa, establece la obligación del Alcalde de comunicar a todos los concejales en el primer pleno ordinario del Ayuntamiento que se celebre tras la sesión constitutiva de la Corporación qué grupos municipales se han constituido, quiénes son sus integrantes y quiénes sus portavoces. Este acto no supone aprobación o intervención alguna por parte del Presidente de la Corporación; es, simplemente, una información al pleno municipal y no tiene otros efectos que la mera comunicación al máximo órgano de gobierno y administración del Ayuntamiento.

No todos los legisladores autonómicos han contemplado este último trámite del procedimiento de constitución de los grupos municipales. Sólo las Comunidades Autónomas de Murcia y de Galicia contienen entre sus disposiciones una previsión con un tenor similar al empleado por el legis- 
lador estatal, según se lee en los artículos 27.4 y 75.3 de sus correspondientes Leyes de Administración Local.

Por lo que respecta a los reglamentos orgánicos municipales que hemos analizado, son excepción los que no contienen una disposición de igual o similar tenor a la estatal. Prácticamente todos han atribuido al Alcalde la obligación de que transcurrido el plazo de que disponen los concejales para constituir grupos municipales y presentado el pertinente escrito por éstos, dé cuenta en el primer Pleno ordinario que se celebre de las cuestiones señaladas, pero únicamente a meros efectos informativos ${ }^{41}$. Los reglamentos orgánicos de Málaga y Vitoria son los únicos que no contienen la previsión señalada, pero entendemos que les resulta de aplicación, como se ha venido señalando, el ROF como Derecho supletorio, por lo que sus respectivos Alcaldes también deberán dar cuenta a sus plenos de estas actuaciones.

\section{Funciones $\mathbf{y}$ atribuciones}

Si bien los grupos municipales surgieron en nuestros Ayuntamientos, según se ha señalado en las primeras líneas de este trabajo, como una realidad fáctica que, después, tuvo un parco reconocimiento legal, lo cierto es que hoy, por las funciones que realizan, se han convertido en los verdaderos protagonistas de la política municipal ${ }^{42}$.

Morell OCAÑa nos enseñó bien tempranamente las funciones que, a favor de sus miembros, pueden desempeñar los grupos políticos. Éstas son tres: $1^{a}$ Mediadora, tanto en relación con el electorado como con los órganos de la Corporación, $2^{\text {a }}$ De apoyo al desempeño de derechos y deberes individuales y $3^{\circ}$ De formación y defensa de una opinión común frente a los problemas de gobierno y administración municipales ${ }^{43}$.

Ahora bien, téngase presente que el autor citado se refiere a las funciones que pueden desempeñar los grupos municipales, pero atendiendo

\footnotetext{
${ }^{41}$ El reglamento orgánico municipal del Ayuntamiento de Granada establece, además, que se constituirá un registro de grupos municipales en el que constará la denominación de cada uno de ellos, la relación de sus miembros y cargos corporativos que desempeñen, así como la representación dentro del grupo... (artículo 188).

${ }^{42}$ D. Loperena Rota, «El pleno del Ayuntamiento», DA núm. 228, oct-dic., 1991, p. 98.

${ }^{43}$ L. Morell Ocaña, El régimen..., cit., pp. 519 y 520. E. Belda Pérez-Pedrero, «Los grupos políticos...», cit., pp. 287 y 288, citando a Morell, señala, sin embargo, que son cuatro los tipos de funciones que ejercen los grupos municipales: de mediación, de apoyo, de ocupación de los órganos que exigen proporcionalidad y de formación o defensa de opiniones.
} 
exclusivamente a los integrantes que los componen, cuando, desde luego, también pueden realizar otras funciones de cara a la propia Corporación municipal, a los ciudadanos a quienes representan, etc., es decir, atendiendo a otros elementos que también forman parte de ellos.

Después de afirmar - muy acertadamente, en nuestra opinión-que los grupos políticos desempeñan una función complementaria e instrumental, ROMERo HeRnÁndez ${ }^{44}$ destaca como principales manifestaciones de ésta las siguientes:

- Servir como instrumentos de preparación de la actuación del grupo, tanto mediante la recepción de la voluntad del electorado, como facilitando la información necesaria para el desarrollo del trabajo de grupo y los concejales que la integran.

- Facilitar la expresión coordinada de la posición política y voluntad del correspondiente grupo en los órganos necesarios y resolutivos de la Corporación, sin perjuicio de los derechos individuales de los miembros que la integran.

- Permitir la expresión proporcional de la voluntad del correspondiente grupo en otros órganos complementarios.

A nuestro entender, aunque muy importantes en la vida municipal, los grupos políticos desempeñan funciones complementarias, instrumentales $\mathrm{y}$, sobre todo - se debería añadir - ad intra. En efecto, ejercen funciones complementarias puesto que todas las principales y más relevantes decisiones que se pueden adoptar en el seno de un Ayuntamiento forman parte del haz de competencias de los órganos que tienen atribuido por ley el gobierno y la administración municipal y ellos sólo están fundamentalmente presentes en los órganos que tienen el carácter de complementarios. Sus funciones son, también, instrumentales porque ayudan a conformar la voluntad de los órganos que forman parte del Ayuntamiento bien directamente o bien, a través de sus relaciones con los colectivos sociales y los ciudadanos en general, de manera indirecta. Y, por último, sus funciones carecen de relevancia externa por cuanto carecen de capacidad para adoptar decisiones que afecten a la población de ese municipio; en el funcionamiento ordinario de la institución municipal, mucho más que la voluntad individual de cada uno de los concejales, son los grupos formados por los cargos políticos representativos para lograr un mejor funcionamiento de la Corporación los que expresan, mediante su intervención en los

${ }^{44}$ F. Romero Hernández, Comentarios a la Ley Básica..., cit., pp. 366 y 367. 
correspondientes órganos colegiados, las decisiones políticas, jurídicas, financieras, etc que adoptan nuestros Ayuntamientos.

Pero, a los efectos del presente trabajo, resulta más interesante analizar las atribuciones que el ordenamiento jurídico ha conferido a los grupos políticos municipales con la finalidad de desempeñar las funciones que se acaban de señalar.

La LBRL, en su redacción original, sólo reconocía a los grupos políticos el derecho a participar, mediante la presencia de concejales pertenecientes a los mismos, en los órganos complementarios del Ayuntamiento que tengan por función el estudio, informe o consulta de los asuntos que hayan de ser sometidos a la decisión del Pleno, esto es, las llamadas Comisiones informativas (artículo 20.3) y a formar parte de la Comisión Especial de Cuentas (artículo 116). Así de escueta, como ya nos es conocido era la Ley básica estatal y así de exiguas las competencias atribuidas a los grupos.

A propósito de las Comisiones informativas, el Tribunal Constitucional tuvo ocasión de pronunciarse en su Sentencia 32/1985, de 6 de marzo, respecto de su composición y, después, reiterar su pronunciamiento, entre otras, en la Sentencia 30/1993, de 25 de enero. El «máximo intérprete de la Constitución», después de constatar que ningún precepto constitucional establece expresamente cuál haya de ser la composición de estos órganos y que tampoco el legislador postconstitucional ha regulado esta materia, afirma en su Fundamento Jurídico 2:

«Es claro que la inclusión del pluralismo político como valor jurídico fundamental (art. 1.1 CE) y la consagración constitucional de los partidos políticos como expresión del pluralismo... dotan de relevancia jurídica (y no sólo política) a la adscripción política de los representantes y, en consecuencia, esa adscripción no puede ser ignorada, no por normas infraconstitucionales que regulen la estructura interna del órgano en el que tales representantes se integran, ni por el órgano mismo, en las decisiones que adopte en ejercicio de la facultad de organización que es consecuencia de su autonomía. Estas decisiones, que son, por definición, decisiones de la mayoría, no pueden ignorar lo que en este momento, sin mayor precisión, podemos llamar derechos de la minoría.

Siendo ello así, la composición no proporcional de las Comisiones informativas resulta constitucionalmente inaceptable porque éstas son órganos sólo en sentido impropio y en realidad meras divisiones internas del Pleno, carentes de competencias decisorias propias y cuya función se 
reduce a preparar las decisiones de aquél, estudiando e informando previamente los asuntos sobre los que debe resolver. En cuanto partes del Pleno deben reproducir, en cuanto sea posible, la estructura política de éste, pues, de otro modo, en efecto, no se eliminaría toda participación de los concejales de la minoría en un estadio importante del proceso de división..., sino que se limitaría a la minoría incluso la posibilidad de participar con plena eficacia en el estadio final de la decisión, privándola del tiempo necesario para el estudio en detalle de los asuntos o de la documentación que ello requiere, o de ambas cosas.

... La vinculación de todos los poderes públicos a la Constitución (art.9.1 CE) obliga en consecuencia a los Ayuntamientos al respeto de esta proporcionalidad que, naturalmente, no implica la necesidad de que cada una de las Comisiones sea reproducción exacta, a escala menor, del Pleno Municipal, sino sólo la de que hagan posible, al fijar la composición de las Comisiones se procure dotar de presencia en ellas a las fuerzas políticas presentes en el Pleno».

Tras el reforzamiento de los grupos políticos por la reforma que operó la Ley 11/1999, de 21 de abril, en la LBRL, éstos vieron incrementadas sus atribuciones, pues a las ya señaladas deben añadirse: el derecho a participar en la parte de los Pleno dedicada al control de los órganos de gobierno a través de la formulación de ruegos, preguntas y mociones (artículo 46.2.e); el derecho a percibir, con cargo a los Presupuestos anuales de la Corporación, una dotación económica que posibilite su funcionamiento (artículo 73.3) y, en virtud de lo dispuesto en la Ley Orgánica de Régimen Electoral General tras la modificación llevada a cabo por la Ley Orgánica 8/1999, de 21 de abril, a participar en las sesiones donde se discuta una moción de censura (artículo 197.1.e).

Ni las leyes autonómicas que han versado sobre el régimen o la Administración local ni los reglamentos orgánicos municipales, prácticamente, se han ocupado de esta cuestión.

Las primeras - y sólo nos podemos referir a las de Galicia y Aragónrecogen el derecho de los grupos políticos a designar a aquellos de sus componentes que hayan de representarlos en todos los órganos colegiados, es decir, engloba de esta manera tanto a las Comisiones informativas como a la Comisión Especial de Cuentas y a cualquier otro órgano colegiado, temporal o permanente, que pueda crearse en la organización municipal (artículos 77 y 111.1, respectivamente). Además, las citadas leyes autonómicas y el Texto refundido de régimen local y municipal de Cataluña han aclarado en sendos preceptos que las funciones y atribuciones correspon- 
dientes a los grupos políticos se entienden, en cualquier caso, sin perjuicio de las que la legislación de régimen local atribuya a los órganos municipales y a los miembros de la Corporación (artículos 78, 111.2 y 51 de los textos legales mencionados), lo que, a nuestro juicio, quiere significar que los grupos políticos para desempeñar las funciones para las que se han constituido no pueden ejercer aquellas que normativamente están atribuidas a los órganos de los que forman parte los grupos municipales ni las que correspondan a los miembros de la Corporación de manera individual, aunque estén agrupados $\mathrm{y}$, en cierta forma, sometidos a la disciplina del grupo político del que forman parte.

Los reglamentos orgánicos municipales, por su parte, tampoco destacan por lo que han regulado sobre este tema. Lo más que han alcanzado algunos ha sido a disponer las atribuciones que ya señalan las leyes estatal y autonómicas, pero sin mayor desarrollo, es decir, que tienen derecho a participar, mediante la presencia de concejales pertenecientes a los mismos, en los órganos complementarios que tengan por función el estudio, informe o consulta de los asuntos que hayan de ser sometidos a la decisión del Pleno, en concreto las Comisiones informativas y Comisión Especial de Cuentas ${ }^{45}$. El Ayuntamiento de Cartagena ha sido el que con mayor detalle ha recogido las atribuciones de los grupos municipales al establecer en el artículo 19 que éstos tienen derecho a :

a) A tener en las Comisiones que se formen el mismo número de votos que le corresponden en el Pleno (voto ponderado).

b) A reclamar una distribución proporcional del tiempo reservado a las intervenciones dentro de cualquier debate.

c) A asumir la iniciativa sin perjuicio de los derechos individualmente reconocidos al concejal, pudiendo poner en marcha, impulsar o solicitar la cancelación de cualquier tipo de acto municipal siempre que se cumplan las condiciones que este reglamento determine.

d) A ejercer cualquier otra función que le corresponda.

Ha sido el ROF, a lo largo de su articulado, la norma que más ha concretado las atribuciones que corresponden a los grupos políticos.

Así, establece en su artículo 29 el derecho de los grupos a participar en los órganos complementarios del Ayuntamiento, disponiendo a tal efecto que es a aquellos a quienes corresponde designar, mediante escrito de su

\footnotetext{
${ }^{45}$ Vid. los artículos 33 del reglamento del Ayuntamiento de Gijón, 187.1 del reglamento granadino y 12 del reglamento de La Coruña.
} 
portavoz al Presidente y en los términos previstos en cada caso en el propio ROF, a aquellos de sus componentes que hayan de representarlos en todos los órganos colegiados integrados por miembros de la Corporación pertenecientes a los diversos grupos. Y, antes, en los artículos 27 y 28 les atribuye el derecho a disponer de un despacho o local para reunirse de manera independiente y recibir visitas de los ciudadanos, en la sede misma del Ayuntamiento si las disponibilidades funcionales de la organización administrativa de la Entidad local lo permiten, y hacer uso de los locales de la Corporación.

Es en el Título dedicado al funcionamiento de los órganos necesarios de los Entes locales territoriales y, más en concreto, en su Capítulo Primero, que lleva por rúbrica «Funcionamiento del Pleno», donde se hallan el resto de atribuciones asignadas por el ordenamiento jurídico a los grupos municipales.

En efecto, el artículo 82.1 posibilita que los portavoces de los grupos existentes en la Corporación puedan participar en la elaboración del orden del día de la correspondiente sesión plenaria si el Alcalde les consulta ${ }^{46}$. También, en virtud de lo dispuesto en el artículo 87, los grupos pueden solicitar del Presidente que interrumpa la sesión para deliberar por separado sobre la cuestión que se está debatiendo, a efectos de adoptar una postura conjunta. Asimismo, los grupos tienen derecho a ocupar un lugar determinado en el salón de sesiones, que será decidido por el Alcalde, oídos los portavoces, teniendo preferencia el grupo formado por los miembros de la lista que hubiera obtenido mayor número de votos (artículo 89). Los grupos políticos pueden, según dispone el artículo 91.4, proponer la inclusión de asuntos de urgencia, no contenidos en el orden del día. Igualmente, pueden solicitar la lectura íntegra de aquellas partes del expediente o del informe o dictamen de la Comisión que consideren conveniente para mejor comprensión, a tenor de lo contenido en el artículo 93. Durante el desarrollo del debate, los grupos políticos — prevé el artículo 94.1tienen el derecho a consumir un primer turno respecto de cada asunto, así como de un segundo turno, si lo solicitaran. Otra atribución que ostentan es la de formular ruegos y preguntas, pues el artículo 97 dispone, en primer término, que pueden plantear ruegos los grupos municipales a través de sus portavoces y, en segundo lugar, que, también a través de sus portavoces, pueden plantear las preguntas que consideren de interés. Atendien-

\footnotetext{
${ }^{46}$ Algunos reglamentos orgánicos municipales han dispuesto la creación de la Junta de Portavoces, integrada por el Alcalde y los portavoces municipales, con el carácter de órgano informativo y deliberante. En este sentido, vid. los artículos 34-38 del reglamento de Gijón, 189-194 del de Granada, 31 del de Málaga, 38 del de Salamanca, 32-40 del de Toledo, y 29 del de Valladolid.
} 
do a lo prescrito en el artículo 102.2, los grupos pueden solicitar al Pleno la votación nominal sobre cualquier asunto. Y, por último, respecto de las sesiones extraordinarias cuyo objeto sea someter a debate la gestión de la Comisión de gobierno, los grupos políticos de las Corporación pueden formular a este órgano las preguntas que consideren de interés, que serán contestadas por un miembro de la propia Comisión de Gobierno.

\section{Medios materiales, personales y económicos}

Si la LBRL, en su redacción primitiva, no había dispuesto ninguna previsión respecto de los medios que pudieran ponerse a disposición de los grupos políticos para el cumplimiento de sus funciones, el ROF, por el contrario, estableció en el Capítulo dedicado a éstos dos preceptos que prevén la disponibilidad, en la medida de las posibilidades de cada Corporación ${ }^{47}$, de un conjunto de medios personales y materiales asignados a los grupos políticos destinados al cumplimiento de las misiones encomendadas. En efecto, el artículo 27 indica que los diversos grupos políticos que se hayan constituido dispondrán en la sede de la Entidad local, y en la medida de las posibilidades funcionales de la organización administrativa de ésta, de un despacho o local para reunirse de manera independiente y recibir visitas de los ciudadanos, y el Presidente o el miembro de la Corporación responsable del área de régimen interior pondrá a su disposición una infraestructura mínima de medios materiales y personales; y el artículo 28 amplía los medios materiales que pone a disposición de los grupos políticos al establecer que éstos podrán hacer uso de locales de la Corporación para celebrar reuniones o sesiones de trabajo con asociaciones para la defensa de los intereses colectivos, generales o sectoriales de la población, encomendado al Presidente o al miembro corporativo responsable del área de régimen interior el establecimiento del régimen concreto de utilización de los locales por parte de los grupos de la Corporación, teniendo en cuenta la necesaria coordinación funcional y de acuerdo con los niveles de representación política de cada uno de ellos y prohibiendo que

\footnotetext{
${ }^{47}$ El Tribunal Supremo, entre otras, en sentencia de 12 de diciembre de 2000 (RJ 2001/75) declara, acogiendo los fundamentos de la sentencia impugnada, «que ni del espíritu ni de la letra de la norma invocada (se refiere al ROF) se desprende que automática e inmediata pues el precepto supedita la puesta a disposición de los medios infraestructurales a las posibilidades funcionales de la organización administrativa de la entidad local...», lo que vuelve a reiterar más adelante al declarar «que los grupos no tienen ningún derecho concreto, a medios materiales o personales, sino el que les corresponda de acuerdo con las posibilidades funcionales de la organización administrativa de la entidad local».
} 
este tipo de reuniones coincida con sesiones del Pleno o de la Comisión de Gobierno.

La Ley 11/1999, de 21 de abril, que modificó la LBRL, añadió al artículo 73, como bien es sabido, un tercer apartado que dedicó a los grupos políticos, conteniendo entre sus disposiciones una previsión acerca de los bienes económicos de que podrán disponer éstos ${ }^{48}$. Así es, ya que establece la posibilidad de la asignación de una dotación económica, que atribuirá el Pleno de la Corporación con cargo a los Presupuestos anuales de la misma, para el funcionamiento de estas agrupaciones de cargos públicos, con unos términos — como ha destacado Rodríguez Álvarez ${ }^{49}$ — muy similares a los contenidos en el Reglamento del Congreso de los Diputados. Esta dotación económica deberá contar con un componente fijo, idéntico para todos los grupos, y otro variable, en función del número de miembros de cada uno de ellos, dentro de los límites que, en su caso, se establezcan con carácter general en las Leyes de Presupuestos Generales del Estado, y sin que puedan destinarse al pago de remuneraciones de personal de cualquier tipo al servicio de la Corporación a la adquisición de bienes que puedan constituir activos fijos de carácter patrimonial.

Con anterioridad a esta modificación legal, la asignación de una dotación económica a los grupos políticos municipales para el cumplimiento de sus funciones no tenía habilitación legal alguna ni en la LBRL, ni en el ROF, ni podía ampararse tampoco en el ámbito de la autonomía local, tal y como tenía declarado el Tribunal Supremo ${ }^{50}$.

\footnotetext{
${ }^{48}$ La Redacción de El Consultor, Manual..., cit., p. 174, ha visto en esta previsión una necesidad que se deriva de la pretensión de reforzar la integración de los miembros electivos de las Corporaciones en los grupos políticos.

${ }^{49}$ La reforma del régimen local..., cit., p. 145.

${ }^{50}$ Vid., entre otras, sentencia de 10 de julio de 2000 (RJ 2000/9698). La Sala de lo ContenciosoAdministrativo declara lo siguiente: «el apartado e) relativo a determinadas percepciones de los grupos políticos (se refiere al punto séptimo del Acuerdo del Pleno del Ayuntamiento de Almuñecar de 6 de julio de 1991), sin embargo, debe entenderse que establece una forma de financiación de los grupos políticos, constituidos conforme al artículo $23 \mathrm{ROF}$, que no tiene cobertura legal en la LRBRL, ni en el ROF, y que no puede ampararse en el ámbito de la autonomía local. Dichas normas no prevén una subvención o forma asimilada de financiación que se traduzca en percepciones de cantidades fijas y mensuales, según el número de miembros con alguna delegación. Percepciones que tampoco pueden encuadrarse en la previsión del artículo 27 ROF porque, como tuvimos ocasión de recordar en sentencia de 14 de octubre de 1997, se refiere a que los grupos municipales, en la medida de las posibilidades, puedan disponer de un despacho o local, en sede de la entidad local, y también, en la medida de las posibilidades, de un infraestructura mínima de medios materiales y personales, pero no da cobertura a percepciones fijas por dichos grupos como las que contempla el apartado del acuerdo que se analiza».
} 
El precepto del que se da cuenta finaliza imponiendo a los grupos políticos la obligación de llevar una contabilidad específica respecto de la dotación económica que perciba de la Corporación, que pondrán a disposición del Pleno de ésta siempre que les sea requerido.

En suma, si el ROF dotó, en la medida de las posibilidades de cada Corporación, a cada grupo político de medios materiales, la Ley básica estatal les ha otorgado, también dentro de las disponibilidades de cada Entidad local, de una dotación económica con que hacer frente a su funcionamiento de la vida corporativa.

Las Leyes autonómicas se han mostrado absolutamente parcas, cuando no han omitido regulación alguna sobre este extremo. Ni Canarias ni Aragón ni Cataluña contienen previsión alguno que tenga por objeto los medios materiales y personales que puedan ponerse a disposición de los grupos políticos. Las restantes sí que contienen alguna previsión, aunque se limitan poco menos que a señalar lo que ya ha establecido el legislador estatal. Así, la Ley de Régimen Local de la Región de Murcia contiene un artículo (el 28) cuyo apartado primero señala que los grupos políticos dispondrán en la sede del Ayuntamiento de los locales y medios personales y materiales que permitan las disponibilidades de la Corporación, para poder reunirse de manera independiente; y un apartado segundo que, adelantándose a las decisiones del legislador estatal, indica que los grupos políticos, mediante acuerdo plenario que así lo disponga, podrán contar con asignaciones económicas para atender su funcionamiento. Galicia, en su Ley de Administración Local, cuenta con un precepto (el artículo 79) prácticamente de idéntico tenor a los artículos 27 y 28 ROF. Y, finalmente, la Ley de Administración Local de Madrid pone fin a su artículo dedicado a los grupos políticos municipales señalando que los Ayuntamientos proporcionarán a éstos el acceso a los medios materiales y personales de la Corporación en la medida de sus posibilidades y establecerán la asignación económica que de acuerdo con sus recursos se considere idónea, aunque obliga a que en los municipios de población superior a veinte mil habitantes exista una partida económica específica a estos efectos, esto es, ya no se trata de una libre disposición de la Corporación, sino que, teniendo presentes las disponibilidades del Municipio, esa partida, dotada de mayor o menor cantidad, debe existir (artículo 32.5).

Las normas orgánicas municipales tampoco han sido muy expresivas respecto de esta cuestión, aunque algunas, como se verá, han regulado esta materia con mayor detalle. 
Con carácter general, se puede afirmar que los reglamentos orgánicos examinados se han limitado a señalar, prácticamente, lo mismo que los legisladores estatal y autonómico, esto es, a asignar a los grupos políticos municipales constituidos un despacho o local en la sede del Ayuntamiento para reunirse de manera independiente y recibir visitas de ciudadanos y a poner a su disposición la infraestructura mínima de medios materiales y personales para el desarrollo de sus funciones ${ }^{51}$.

Sorprende, después de que hayamos calificado a la Ley de Régimen Local de Murcia de precursora de la Ley básica estatal en relación la asignación de una dotación económica a los grupos municipales que no se contemplaba con anterioridad, que el reglamento orgánico del Ayuntamiento de Cartagena no haya establecido entre sus disposiciones ninguna previsión al respecto. En efecto, la norma municipal se limita a dedicar un precepto para indicar que los grupos políticos municipales dispondrán en el Ayuntamiento de un despacho o local para reunirse de manera independiente y recibir visitas de ciudadanos que el Alcalde o miembro de la Corporación responsable del área de régimen interior pondrá a disposición de los mismos una infraestructura de medios materiales y personales, pero sin hacer referencia alguna a las asignaciones económicos de que podrían disponer cada grupo para su funcionamiento.

Otros reglamentos orgánicos se han ocupado con mayor amplitud de los medios materiales y personales de que dispondrán los grupos municipales o de las asignaciones económicas a que tienen derecho en función de las partidas asignadas en los presupuestos anuales.

La norma municipal orgánica del Ayuntamiento de Zaragoza ha detallado, de manera singular, el primer extremo indicando en su artículo 30 toda una serie de disposiciones relativas a los medios materiales y personales con que contarán los grupos municipales constituidos y, de este modo, señala que el Ayuntamiento proporcionará a su costa los elementos para que los grupos políticos puedan desenvolverse, quedando garantizado en todo caso: un local con todos sus servicios, incluso telefónico, ubicado en la Casa Consistorial, siempre que sea posible; el mobiliario, material inventariable y objetos de decoración; un auxiliar administrativo para los grupos constituidos por un número inferior al de seis concejales y otro más para aquellos formados por seis o más concejales y, además un titulado medio o superior para los grupos constituidos por cuatro o más conce-

${ }^{51}$ Vid., por todos, los artículos 30 del reglamento orgánico del Ayuntamiento de Gijón y 10 del de La Coruña. 
jales; y el acceso a todos los servicios generales del Ayuntamiento, así como al suministro de material no inventariable.

Los reglamentos orgánicos de los Ayuntamientos de Salamanca y Valladolid son, por su parte, ejemplo de concreción en relación a la dotación económica de que dispondrán los grupos municipales para su funcionamiento. Ambas normas, en sus artículos 37.2 y 28,2 y en términos muy similares, después de disponer lo que ha señalado el legislador básico estatal, es decir, que los grupos políticos dispondrán de una asignación económica para gastos de funcionamiento propios de su actividad municipal que será fijada anualmente en la correspondiente partida presupuestaria y que la misma no podrá destinarse al pago de remuneraciones de personal de cualquier tipo al servicio de la Corporación o a la adquisición de bienes que puedan constituir activos fijos de carácter patrimonial, establece que la dotación económica asignada se distribuirá con el siguiente criterio:

- Un tercio de la cantidad total presupuestada, en partes iguales, entre los grupos municipales.

- El resto, de forma proporcional al número de concejales de cada grupo.

Ambos reglamentos orgánicos, asimismo, hacen hincapié en la obligación de cada grupo de llevar una contabilidad específica de su dotación económica, que deberá ser puesta disposición del Pleno de la Corporación siempre que éste lo pida. 